Schools and their Relation to Technical Institutes and Colleges," by Principal C. L. Eclair-Heath (Newcastle-upon-Tyne); and on "Local Colleges and Adult Education," by Principal L. Small (Bootle).

The suggestions of $\mathrm{Mr}$. Garnett for the establishment of a national system of education in England during the next ten years are embodied in a pamphlet presented to a meeting of the newly formed Federal Council of Lancashire and Cheshire Teachers' Associations in January last. It is accompanied by an elaborate "flow" diagram showing graphically in colour the various types of scholastic institutions suggested, of which as many as sixteen are depicted, ranging from the elementary school upwards to the university, and dealing with school and university life up to the twenty-fifth year. It is declared that "it is the main business of all education to form in the mind of every person a single wide interest centred in a supreme purpose," and that "it is the subordinate business of education to train young people so that they shall be able to realise their central purpose in some particular form of service to their fellows. For example, the particular form of service for which technical and commercial education prepares is that of providing the material wealth without which no community-so different in this respect from an individual-can make much progress towards the fulfilment of high spiritual purposes." The pamphlet proceeds to divide those who are to occupy the various positions in industry, commerce, and other departments of national life into four classes: Leaders in thought and action, about 3 per cent.; skilled managers and assistants, about 17 per cent.; skilled wage-earners, about 40 per cent.; and unskilled labourers and repetition workers, about 40 per cent.

The scheme suggested received the attention of a meeting, held in June last, of the headmasters of secondary schools in Lancashire, Cheshire, Cumberland, and Westmorland, who expressed strong disapproval of its proposals, which they thought too mechanical, and of the suggestion that there should be lower and higher secondary schools. They were not persuaded that it was desirable to prevent the individual growth and development of each school, and that whilst transference and change of grade seemed to be its keynote, the headmasters believed in elasticity, growth, and continuous development.

The purpose of Mr. Coles's paper is to set forth the present unsatisfactory position of technical institutions in this country, and to propose remedies therefor in respect alike of the development of higher education in technical institutions and of the administration thereof, so as to bring them into closer relation with the work of the universities. Mr. Coles advocates the institution of faculties of technology and commerce in connection therewith, and suggests that an investigation should be set up, as in 1882 , into the condition of higher technological education in the United Kingdom.

Mr. Small's paper, accompanied by notes by Principal J. F. Hudson (Huddersfield), deals with local colleges and adult education. The authors advocate the development of the technical institute into "the local college," an official term appearing for the first time in the revised regulations for continuation. technical, and art courses issued by the Board of Education in February, I9I7, so that it shall include not only the training of workers in commerce and in specific industries, but also their continued education as citizens by the introduction of humanistic studies, and to provide generally for non-vocational subjects of a literary, scientific, and recreative character, together with facilities for the study by adult workers of quesNO. 2649 , VOL. IO5] tions calculated to promote a better understanding of the character and problems of social life. Already with this end in view the Huddersfield Technical College has entered into close relations with the York. shire District Council of the Workers' Educational Association.

Mr. Eclair-Heath in his paper declares that the idea of continuation schools is not new, and instances the excellent example of the Royal Dockyard Schools at Deptford and elsewhere. He says that early vocational education is undesirable, and that the schools should be held apart from works. He favours mixed schools and the introduction of religious instruction, and suggests that there should be set up a system of selection whereby only suitable students should be allowed the privilege of continued education up to eighteen years of age.

Resolutions were adopted welcoming a large development of humane studies in the constituent institutions of the association in connection especially with adult education :- "That the association accepts the description of the work of a 'local college' contained in Appendix III. of the Draft Regulations of the Board of Education for continuation, technical, and art courses in England and Wales"; and "That each local college should be the recognised centre for the organisation of educational courses for adults in its area and for the supply of qualified lecturers and class tutors and adequate library and other facilities." It was resolved to refer to the council the question that the Board of Education should be asked to accept as "recognised service" the services of teachers engaged in organisation, supervision, and inspection with the view of qualifying such persons for pension under the recent Superannuation Act, and that the Board should furnish to every teacher of forty-five years of age and upwards a statement of his position as to the perjod of "recognised service " and "qualifying service" at present placed against his name for the purpose of pension.

\section{The Asiatic Origin of Man. ${ }^{1}$}

THE author of the speculative paper referred to below is an evangelist of the gospel of evolution according to Dr. W. D. Matthew. The idea of the Asiatic origin of the dominant orders of mammals, in its source as old as Buffon, was in IgI5 placed on a firm basis by Matthew in his paper "Climate and Evolution." This idea Dr. Griffith Taylor now takes up and applies to the case of man. Penck's fourfold subdivision of the Ice Age is regarded as applying generally, and the development of the prehistoric races in Asia is presumed to occur in the successive mild periods as follows:

\section{Chellian and Acheulian. Pliocene.}

Mousterian.

Aurignacian, Solutrean, and Magdalenian. Azilian and Neolithic. Bronze-using Races. Mongolians.

\section{Gunz-Mindel.}

Mindel-Riss.

Riss-Würm.

Post-Glacial.

Late Post-Glacial and Iistoric.

The following Ice Age in each case and in postGlacial times the progressive desiccation of Asia are presumed to have caused migration from the homeland to the peripheral continents. The migrations are thus fairly well timed to enable the respective races to keep their appointments in Europe, with, perhaps, the exception of the Chellians, Acheulians, and Mousterians, who are too early, if we may judge 1 "Climatic Cycles and Evolution." By Dr. Griffith Taylor. Geo. graphical Review, December, 19rg. 
by Penck's placing of these culture stages, which, however, rests only on indirect evidence.

Taking as his criteria of evolutionary advance four characters, namely, (I) cephalic index, (2) orbital index, (3) hair section, and, in a modified degree, (4) skin colour, Dr. Griffith Taylor then attempts an analysis of the existing races of mankind, and, so far as the available data permit him, shows that the more primitive races, or those with low cephalic and orbital indices and relatively flattened hair section (generally associated with depth of slkin colouring), have been thrust to the more distant parts, from a migrant's point of view, of the outlying continents. Closer in to the centre of distribution come races with successively higher indices, rounder, straighter hair, and reduced colouring, passing through brown, olive, and white to the yellow, brachycephalic, and excessively straight-haired Mongolians, who are the last development of all. So far this is Dr. W. D. Matthew elaborated. A new element is now, however, introduced into the discussion, for an attempt is made to correlate the living with the prehistoric races. One remembers Sollas's tentative comparisons in I9II ("Ancient Hunters"), viz. Tasmanian with Eolithic or Early Palæolithic, Australian with Mousterian, Bushman with Aurignacian, and Eskimo with Magdalenian. The author now postulates direct descent for these and many other races too numerous to mention here.

To bring out the nature of the climatic impulse that is supposed to have initiated the successive waves of migration from the homeland in Asia, the author employs the analogy of the seasonal oscillation of the belts of tropical rains, desert, and polar rains in Australia. As he effectively remarks, Nature has placed Australia like a blackboard, on which are recorded the results of the mobile but very regular and lawabiding climatic zones of the southern hemisphere. He brings forward evidence to show that these zones underwent an analogous migration during the climatic oscillations of the Ice age.

The analysis outlined above forms parts i.-iii. of the paper. The general exposition of the argument is crude, and, were it not for the explicitness of the diagrams, would be difficult to follow. This tabulating and precise definition of material largely speculative gives an illusory impression of the state of the subject, but, if the reader is not misled by it, it certainly conduces to clearness. The adroit handling of a subject so as to distinguish fact and legitimate inference from mere speculation is the last art of the scientific writer.

The remainder of the paper is devoted to geological speculations of less interest. Part iv. is an exposition of Chamberlin's theory of cyclic change. Chamberlin's writings (1897-190I) on the subject are not, however, quoted, the principal authority relied on being Schuchert (xg14). In this section a table of roughly approximate temperatures is given for the periods from the Triassic to the present. That this type of tabulated speculation is dangerous is instanced by the fact that both zoological and botanical evidence show that the temperature of Europe in the Neolithic period was several degrees higher than it is at the present day, instead of $7^{\circ} \mathrm{F}$. lower, as stated.

Part v. is an estimate of geological time based on various authorities. The statement is made that "Joly quotes similar figures, indicating about $300,000,000$ as the time interval since the same epoch" (the Cambrian). It is difficult to conceive the author's motive, if any, for this implicit misrepresentation of the works cited, for it matters not a straw to his theory whether the interval since the Cambrian is $300,000,000$ or less than $100,000,000$ years, as concluded by Joly.

NO. 2649 , VOL. IO57
Part vi. is a suggestion, on astronomical lines, of rhythmic oscillations of climate, etc. It is on a par with many former theories of the Ice age in assigning a cause which there is no independent evidence to show was ever operative.

Papers such as this which deal in giddy speculation have for some time past been looked at askance by the more puritanically minded of our elder geologists. We are not sure that they deserve the contempt with which they are treated. In this matter, however, there is a golden mean, and we should have preferred to see the present paper made less comprehensive, and the leading subject-matter of human migrations more thoroughly dealt with. It is of no use trying to straighten out the universe in an article. W. B. WRIGHT.

\section{Long-range Forecasting in Java.}

PUblilition No. 5, 1919, of the Royal Observatory of Batavia, entitled "Atmospheric Variauons of short and Long Duration in the Malay Archipelago and Neighbouring Kegions, and the Possibility to Forecast 'Them," by Dr. C. Braak, embodies the results of a long investigation into the sequence of rainfall in the equatorial regions east of the Indian Ocean. Three kinds of variation are studied : (I) with periods of one or more years up to and including the sun-spot period, (2) secular variations, and (3) with periods less than a month, comparable with Abbot's short-period solar fluctuations. The variations, the period of which is intermediate between (I) and (3) above, are treated as disturbances of (I). Dr. Braak lays much stress on a three-year period, of the persistence of which he gives plausible, though not quite convincing, examples. He classifies three groups of years, of high barometer, low barometer, and transition (from high to low), but naturally finds a proportion of years not strictly true to any of these types. It is scarcely surprising that he finds in general a correlation between barometric pressure and rainfall. For the east monsoon he finds strong positive correlation between high pressure and drought, and weaker between low pressure and excess of rain. For the west monsoon he finds, with some local exceptions, excess of rain with high barometer, and deficit with low barometer. His problem is thus reduced to the intensity of the correlation and the chances of a correct forecast of the barometer variation. His next step takes into account temperature changes which may be expected to modify pressure conditions, but his result is disappointing. He obtains rules, but their application is so far a failure that they appear to break down most thoroughly in years of droughtthat is, when, if correct, they would be most valuable.

Turning to secular variations, he finds no evidence of progressive change in Batavian rainfall; in fact, the only progressive change on which he lays stress is in Batavian air-temperature. Comparison with stations in India, Australia, and other places in the same quarter of the globe provides other types of change, but none agreeing with Batavia, and the question is left unsolved.

There remain the short-period pressure waves. The equatorial manifestations of these he attributes to a kind of surge, caused by the great disturbances in higher latitudes, exercising a sucking influence or its converse, with slight variations of the rainfall, less than ro per cent. of the normal, the effect of which is to compensate the pressure difference by cooling or heating air probably above the 3000 -metre level.

Other variations of rainfall, humidity, and cloudiness he considers to be local, and, on the whole, rejects 